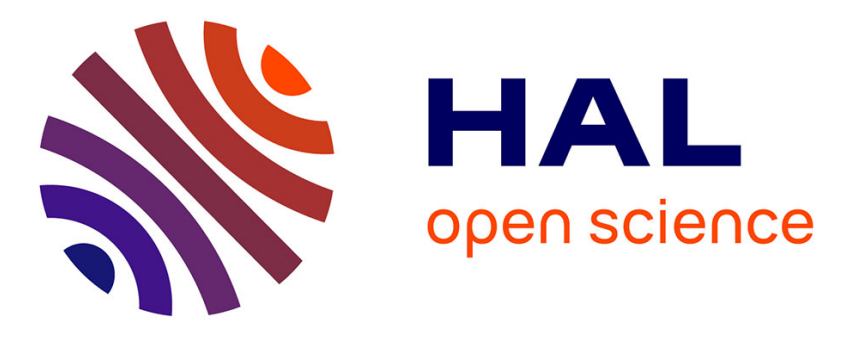

\title{
Regular poly(para-phenylene) films bound to gold surfaces through the electrochemical reduction of diazonium salts followed by electropolymerization in an ionic liquid
}

\author{
Stéphanie Descroix, Géraldine Hallais, Corinne Lagrost, Jean Pinson
}

\section{To cite this version:}

Stéphanie Descroix, Géraldine Hallais, Corinne Lagrost, Jean Pinson. Regular poly(para-phenylene) films bound to gold surfaces through the electrochemical reduction of diazonium salts followed by electropolymerization in an ionic liquid. Electrochimica Acta, 2013, 106, pp.172-180. 10.1016/j.electacta.2013.05.063 . hal-00841286

HAL Id: hal-00841286

https://hal-univ-rennes1.archives-ouvertes.fr/hal-00841286

Submitted on 4 Jul 2013

HAL is a multi-disciplinary open access archive for the deposit and dissemination of scientific research documents, whether they are published or not. The documents may come from teaching and research institutions in France or abroad, or from public or private research centers.
L'archive ouverte pluridisciplinaire HAL, est destinée au dépôt et à la diffusion de documents scientifiques de niveau recherche, publiés ou non, émanant des établissements d'enseignement et de recherche français ou étrangers, des laboratoires publics ou privés. 


\section{Graphical Abstract}

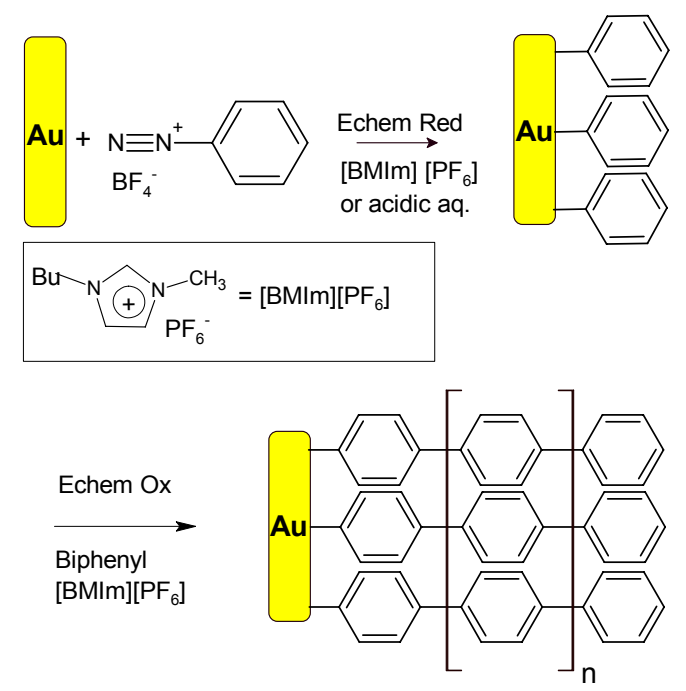

KeyWords: Poly(para-Phenylene), Ionic Liquid, Diazonium, Biphenyl, Electrochemistry 


\title{
Regular Poly(para-Phenylene) films bound to gold surfaces through the electrochemical reduction of diazonium salts followed by electropolymerization in an ionic liquid
}

\author{
Stéphanie Descroix ${ }^{¥}$, Géraldine Hallais ${ }^{\ddagger}$, Corinne Lagrost $\dagger^{*} *$ and Jean Pinson ${ }^{\S, *}$ \\ ${ }^{*}$ Laboratoire Physicochimie Curie, CNRS/UMR 168, 11 rue Pierre et Marie Curie, Paris, France. \\ $\checkmark$ Sciences Chimiques de Rennes, Equipe MaCSE, CNRS UMR 6226, Université de Rennes 1, Campus de \\ Beaulieu, 35042 Rennes, France. \\ ${ }^{\S}$ Physico-Chimie des Electrolytes, des Colloïdes et Sciences Analytiques, ESPCI ParisTech, CNRS UMR \\ 7195,10 rue Vauquelin, 75231 Paris Cedex 05 and Univ Paris Diderot, Sorbonne Paris Cité, ITODYS, UMR \\ 7086 CNRS, 15 rue J-A de Baïf, 75205 Paris Cedex 13, France. \\ *Alchimer, 15 rue du Buisson aux Fraises, 91300 Massy, France.
}

\begin{abstract}
By combining the electroreduction of diazonium salts and the electropolymerization of conducting polymers in an ionic liquid, the electrografting of a regular poly(para-phenylene) film on a gold substrate is achieved, leading to the strong and robust anchoring of the PPP polymers on the substrate ( $A u$-PPP hybrid). A thin layer covalently bound to the substrate is first prepared by the reduction of benzenediazonium salt (BD), then, on top of this layer, a thicker layer of poly(para-phenylene) (PPP) is easily grown by the electrochemical oxidation of biphenyl in the $[\mathrm{BMIm}]\left[\mathrm{PF}_{6}\right]$ ionic liquid. The resulting material is thoroughly characterized by IR, ToF-SIMS and fluorescence spectroscopies. The analyses show the formation of well regular PPP layers that are wired to the substrate. The key role of the $[\mathrm{BMIm}]\left[\mathrm{PF}_{6}\right]$ ionic liquid in the structuration of the polymer is emphasized.
\end{abstract}

Keywords: Surface, Electrografting, Diazonium, Polyparaphenylene

\footnotetext{
* Present adress : Institut d'Electronique Fondamentale, Bat. 221, Rue Andre Ampère, Université Paris Sud 91405, Orsay cedex, France.
} 


\section{Introduction}

Electrografting of diazonium salts is now a well-established method, [1-27] which provides very easily polyaryl layers covalently bound [8-10] to carbon, various metals, semiconductors, inorganic materials and polymers. For example the binding energy on gold has been calculated as $24 \mathrm{kcal} \cdot \mathrm{mol}^{-1}$ and $70 \mathrm{kcal} \cdot \mathrm{mol}^{-1}$ on $\mathrm{Si}(111)-\mathrm{H}$ [11]. The formation of a polyphenylene (PP) layer takes place by electrochemical reduction of benzenediazonium tetrafluoroborate (BD) through the transfer of one electron leading to the formation of a phenyl radical that subsequently attacks the electrode surface and then the first grafted layer. This leads to the formation of conjugated but absolutely disordered polyphenylene layers.[12] This is a major difference with Self Assembled Monolayers (SAMs) of thiol on gold that provide less strongly bound but well-organized monolayers [13].

On the other hand, $\pi$-conjugated polymers have been widely investigated both because of their interesting structure and because of their potential applications in molecular electronics and light-emitting devices [14-17]. Among these conjugated polymers (polythiophenes, polyphenylenevinylenes, polyaniline....) [18], poly(para-phenylene) (PPP) is particularly interesting [19,20], for its high electrical conductivity when doped [21], its blue light emission [22-26], its thermal stability [27], its mechanical properties [28]. PPP is an excellent candidate for many optoelectronics applications in light-emitting diodes (LEDs) [14], field-effect transistors [29], or photovoltaic cells [30]. The synthesis of PPP has been reviewed [19], and different routes have been proposed, including: i) the polymerization of benzene by a catalystoxidant system (Kovacic's method), ii) catalytic and thermal aromatization of poly(1,3cyclohexadienes) iii) Suzuki coupling reactions [20,31], but iv) also copper catalyzed polymerization of diiodobenzene [32] and v) anodic electropolymerization [19,33]. On the whole, this polymer is difficult to process mostly when unsubstituted [19]. In this connection, the anodic electropolymerization of benzene or biphenyl to PPP is a particularly efficient 
synthetic method for the formation of PPP films directly on a substrate in a one-step reaction [33]. However, the electrochemical oxidation of benzene or biphenyl still remains a quite challenging process as water and nucleophiles must be absolutely excluded, leading to the use of concentrated sulfuric acid [34], perchloric acid [35], liquid $\mathrm{SO}_{2}$ [36] or very dry organic solvents such as dichloromethane $[37,38]$. In this context, room-temperature ionic liquids have been highlighted as promising media for the electropolymerization to conducting polymers $[33,39]$. The ionic liquids that are room temperature liquid salts exhibit various physical and chemical properties $[33,40]$. They are entirely composed of ions, and mostly of organic cations, allowing the quasi unlimited tuning of their structures. As such, they are ideal materials for applications that can take advantage of their ionic conductivity [41]. They have been shown to be valuable alternative media for growing PPP by electrochemical oxidation. Indeed, Endres et al.[42,43], and Ivaska et al.[44], successfully used imidazolium-based ionic liquids to produce PPP onto platinum or gold electrodes. For instance, by using the 1-hexyl-3methylimidazolium tris(pentafluorethyl)trifluorophosphate ionic liquid as electrolyte, in a glove box, a thick PPP film was deposited at a Pt substrate from the electrochemical oxidation of benzene [42]. The resulting PPP film was highly regular with a conjugation length ranging between 19 and 21 [43]. However, the electrosynthesized PPP film is not covalently bound to the substrate. Actually, the electropolymerization method has been often compared to the electrodeposition of metals because the organic films are physically adsorbed on substrate surface instead being bound to the electrode surface [33]. In sharp contrast, the covalent bonding of the films onto the surface allows reaching the desirable control of the substrate/PPP film interface, leading to strong and long-term adhesion of the polymer layers on the substrate and giving a remarkable chemical stability of the materials.

Based on the combined use of two well-recognized electrochemical techniques for surface modification, this paper describes the formation of a regular PPP film covalently bound to 
gold substrates, forming an $A u$-PPP hybrid material. Our strategy, rather simple to operate, consists in a two-step procedure that is summarized on Scheme 1. First, a layer of polyphenylene is electrografted on gold thanks to the electrochemical reduction of BD either directly in 1-butyl-3-methyl-imidazolium hexafluorophosphate $[\mathrm{BMIm}]\left[\mathrm{PF}_{6}\right]$, ionic liquid or in aqueous acidic solution, the experimental conditions being chosen in order to produce a layer as thin as possible. The modified surface is then used as an anode for the electrochemical polymerization of biphenyl in $[\mathrm{BMIm}]\left[\mathrm{PF}_{6}\right]$ to obtain a regular PPP film bound to the surface. A similar strategy in aqueous $\mathrm{H}_{2} \mathrm{SO}_{4}$ has been described to deposite polyaniline on a polyaryl layer obtained by reduction of a diazonium salt at a carbon surface [45]. Although the sublayer displayed electron transfer blocking properties towards hydroxymethylferrocene, the modified surface permitted the further electrochemical formation of polyaniline and the resulting material exhibited higher chemical stability and higher resistance to ultrasonic treatment [45]. In this work, a specific attention was paid on the characterization i) of the films structure for showing the regular substitution of the polymer chains on the one hand and ii) of the substrate/films interface for evidencing the covalent bonding on the other hand. Thus the formation of regular poly(para-phenylene) film (PPP) (vs of that of disordered polyphenylene (PP)) was followed through their IR fingerprints in the out-of-plane region that is characteristic of the aromatic substitution and the key role of the ionic liquid in the structuration of the electrochemically synthesized material was emphasized. A careful analysis of the modified substrates using ToF-SIMS spectroscopy was undertaken to clearly evidence the binding of PPP to gold substrate. The preparation of PPP films directly attached by a covalent bond to a metallic substrate can be of interest in many applications, in particular when there must be an electrical contact between the film and an electrode. 

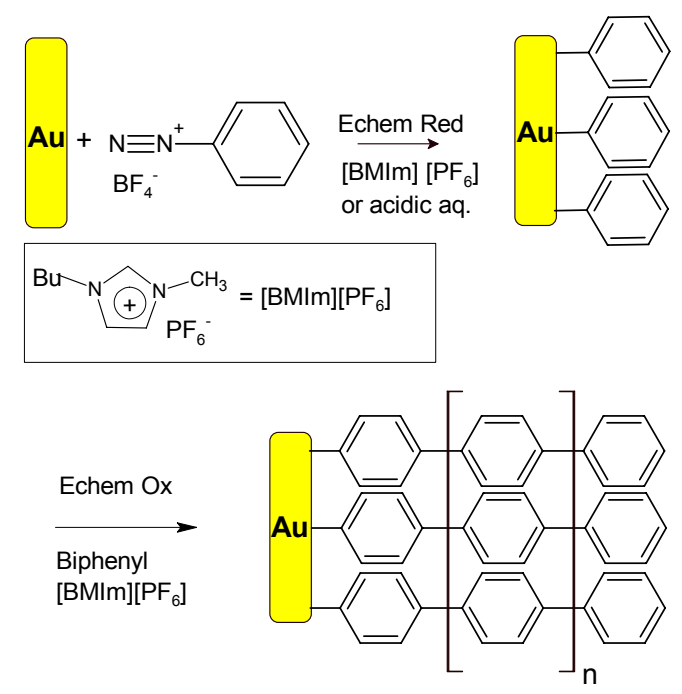

Scheme 1: Procedure for producing regular PPP films covalently attached onto gold substrate.

\section{Experimental}

\subsection{Chemicals and substrates}

Biphenyl was obtained from Aldrich and used without further purification. BD was synthesized in aqueous acidic solution from an ice cold solution of the corresponding aniline $(1.0 \mathrm{mM})$ in $\mathrm{HBF}_{4}(48 \%)$ by the slow addition of $\mathrm{NaNO}_{2}(1.1 \mathrm{mM})$ dissolved in the minimum amount of water. The precipitate was filtered, washed with ether, and dried in vacuum. It was purified by dissolving in $\mathrm{ACN}$ and reprecipitating with ether. Alternatively, the BD is generated in situ in aqueous acidic solution as previously described by Bélanger and coworkers [46]. $[\mathrm{BMIm}]\left[\mathrm{PF}_{6}\right]$ ionic liquid was prepared according to previously published procedure [47]. The ionic liquid was purified by extensive washing with deionized $\mathrm{H}_{2} \mathrm{O}$, filtered over $\mathrm{SiO}_{2} /$ neutral alumina. Prior to each experiment, the ionic liquid was carefully dried overnight by vacuum pumping at $50^{\circ} \mathrm{C}$.

The substrates consisted in $1 \mathrm{~cm} \times 1 \mathrm{~cm}$ gold coated wafers (Aldrich, gold coated silicon wafer, $100 \mathrm{~nm}$ coating, referred thereafter as gold wafer) were cleaned with $98 \%$ 
$\mathrm{H}_{2} \mathrm{SO}_{4}$, rinsed under sonication for $10 \mathrm{~min}$ in Milli-Q water and dried under a stream of nitrogen. The modified surfaces were rinsed with acetone, ultrapure water and dried under nitrogen.

\subsection{Instrumentation}

Electrochemical experiments were performed with an EG\&G 263A potentiostat/galvanostat and an Echem 4.30 version software. The counter electrode was a platinum foil in both $\mathrm{ACN}$ and ionic liquid; the reference electrode was an $\mathrm{Ag} / \mathrm{AgCl}$ reference in ACN while a platinum wire was used as a quasi-reference in the ionic liquid.

IR spectra of modified plates were recorded using a purged (low $\mathrm{CO}_{2}$, dry air) Jasco FT/IR-6100 Fourier Transform Infra Red Spectrometer equipped with MCT (mercurycadmium-telluride) detector. For each spectrum, 1000 scans were accumulated with a spectral resolution of $4 \mathrm{~cm}^{-1}$. The background recorded before each spectrum was that of a bare substrate thoroughly cleaned prior to IR measurements.

The thicknesses of the films on Au were measured with a mono wavelength ellipsometer Sentech SE400. The following values were taken for gold: $\mathrm{ns}=0.153, \mathrm{ks}=3.567$. These values were measured on clean surfaces before grafting and the film thicknesses were determined from the same plates after modification, taking $n_{s}=1.46, k s=0$ for the polymeric layer.

To record the fluorescence image, the modified gold plate was monitored by an inverted fluorescence microscopic system (IX-71, Olympus) equipped with a spectral filters, 410-490 nm and a 100W mercury lamp. A camera CCD 1388x1038 pixels Pike (RD Vision) was mounted on the microscope and Hiris software (RD Vision) was used for camera control and image processing. The image was obtained from a two-pot sample 
ToF-SIMS analyses were obtained with an ION-TOF IV with $\mathrm{Au}^{+}$primary ions at $25 \mathrm{keV}$, the analyzed zone was $150 \mu \mathrm{m}^{2}$ and the acquisition time $75 \mathrm{~s}$. Blank samples were analyzed in the same run as the modified samples. The peak intensity refers to the area of the peak normalized to the total intensity of the spectrum. The image was obtained with $\mathrm{Au}_{3}{ }^{+}$ions for 100 scans $(\sim 40 \mathrm{~min})$.

\section{Results and Discussion}

\subsection{Electropolymerization of biphenyl to PPP in the ionic liquid}

As a preliminary experiment, a PPP film was prepared by oxidation of biphenyl (à.c = $0.2 \mathrm{M})$ in the $[\mathrm{BMIm}]\left[\mathrm{PF}_{6}\right]$ ionic liquid. The gold electrode potential was swept between 0 and $2.5 \mathrm{~V} v s \mathrm{Pt}$ (quasi-reference) at $0.1 \mathrm{~V} / \mathrm{s}$ (figure 1, top). The film is then simply rinsed with acetone and dryed under a gentle stream of Ar. As shown on figure 1 (left, bottom), this simple treatment leads to the delamination of the film from the surface. This observation exemplifies the fact that the films prepared by oxidation of biphenyl in the ionic liquids are poorly adherent to the surface as already described in the literature $[33,43]$. Figure 1 (right, bottom) shows the IRRAS spectrum of the film. It is fully similar to that described in the literature for a regular PPP [43]. The out of the plane vibrations of the aromatic hydrogens are characteristic of the substitution of the aromatic ring [48] and a thorough analysis of these vibration band allow to assess the formation of regular PPP material in contrast to disordered PP. PPP can be then characterized through the ring vibrations bands at 1482 and $1398 \mathrm{~cm}^{-1}$ and by the following bands: $1001 \mathrm{~cm}^{-1}$ (in plane aromatic C-H vibration), $812 \mathrm{~cm}^{-1}$ (out of plane aromatic C-H vibration for 1,4- disubstituted benzene), $763 \mathrm{~cm}^{-1}$ (out of plane aromatic C-H vibration for monosubstituted benzene), $696 \mathrm{~cm}^{-1}$ (ring distortion deformation of monosubstituted benzene) [19]. On the contrary, disordered PP can be distinguished through the appearance of multiple bands in the 800 and $1000 \mathrm{~cm}^{-1}$ region $[38,49,12]$. 

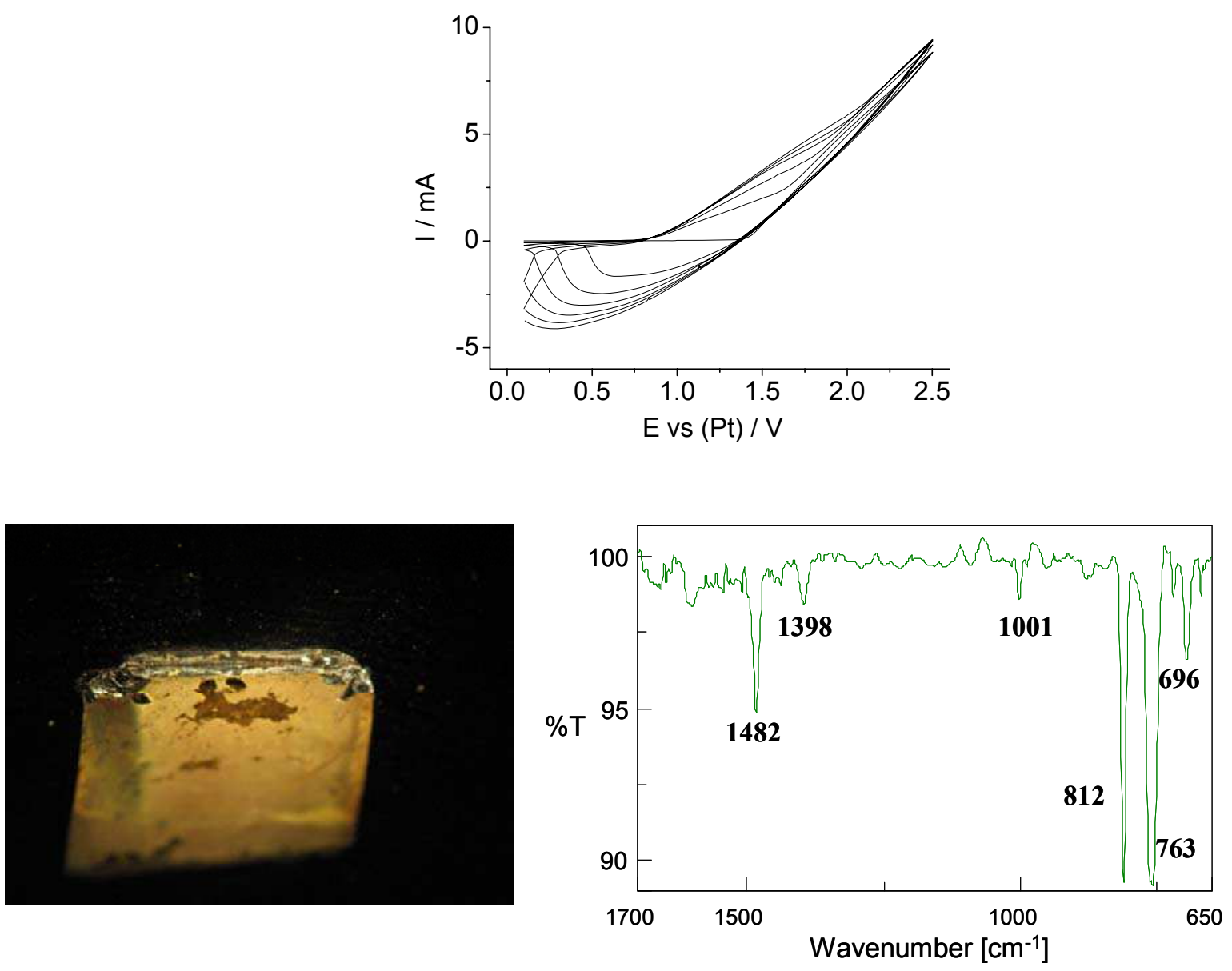

Figure 1. Top : Electropolymerization of $0.2 \mathrm{M}$ of biphenyl in BMIPF6 at $0.1 \mathrm{~V} / \mathrm{s}$ onto a gold electrode, 6 scans. Bottom : Image of a gold wafer modified by oxidation of biphenyl $(0.2 \mathrm{M})$ in $[\mathrm{BMIm}]\left[\mathrm{PF}_{6}\right](10$ cycles between 0.1 and $2.5 \mathrm{~V} / \mathrm{Pt}$ at $0.1 \mathrm{Vs}^{-1}$ ) and rinsed in acetone (note the delamination of the film) and IRRAS spectrum of the same surface.

\subsection{Electrochemical reduction of BD leading to disordered PP films.}

To validate our two-step strategy, three gold wafers were modified by the electrochemical reduction of diazonium salt (Figure $2 \mathrm{a}, \mathrm{b}, \mathrm{c}$ ) either in an aqueous medium (plate a), acetonitrile (ACN, plate b) or $[\mathrm{BMIm}]\left[\mathrm{PF}_{6}\right]$ (plate $\left.\mathrm{c}\right)$. In order to compare with PPP layers described below, plates a and $\mathrm{b}$ were prepared under experimental conditions where rather "thick" layers should be obtained. Practically, for plate a) the potential is hold at $-0.7 \mathrm{~V} /$ $(\mathrm{Ag} / \mathrm{AgCl})$ for $300 \mathrm{~s}$ in cold $10 \% \mathrm{HCl}$ containing $10 \mathrm{mM}$ of aniline and $11 \mathrm{mM}$ of sodium nitrite; when plate $b)$ is hold at $-0.7 \mathrm{~V} v s(\mathrm{Ag} / \mathrm{AgCl})$ for $30 \mathrm{~s}$ in $\mathrm{ACN}+0.1 \mathrm{M} \mathrm{NBu} \mathrm{BF}_{4}+1$ 
$\mathrm{mM}$ of $\mathrm{BD}$, and for plate $c$ ) two potential cycles between +0 and $-1.3 \mathrm{~V} v s$ Pt in $[\mathrm{BMIm}]\left[\mathrm{PF}_{6}\right]$ $+5 \mathrm{mM}$ BD were performed.
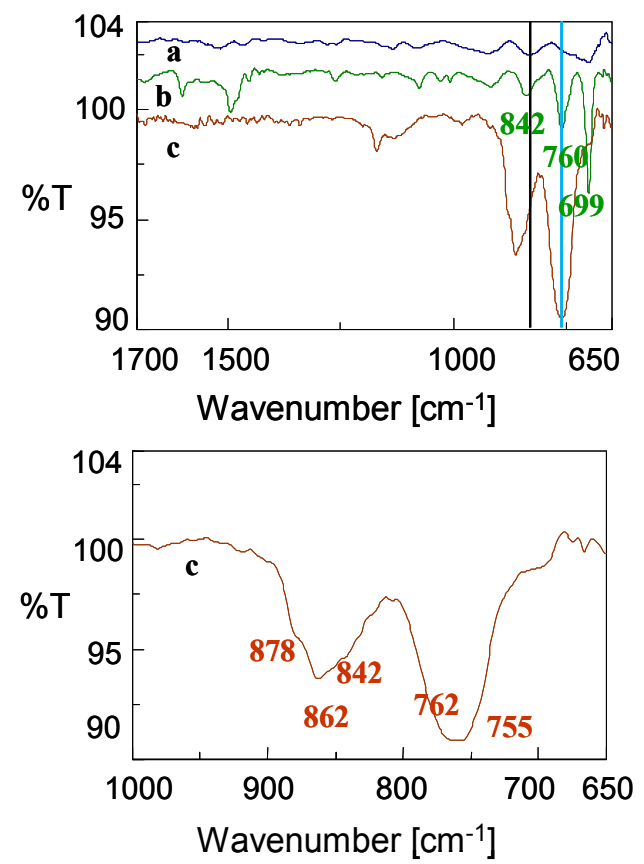

Figure 2. IRRAS spectra of gold plates modified by the electrochemical reduction of BD a) in an aqueous acidic solution (the salt is generated in situ), b) in $\mathrm{ACN}$ c) in $\left[\mathrm{BMIm}^{-}\left[\mathrm{PF}_{6}\right]\right.$.

The corresponding IRRAS spectra were then recorded and compared to evaluate whether the films were disordered or not (Figure 2). The 699 and $842 \mathrm{~cm}^{-1}$ of Figure $2 \mathrm{~b}$ as well as the many bands of Figure 2c are indicative of multisubstitution of the aromatic rings, clearly showing the disordered structure of the PP layers whatever the solvent used to carry out the electrochemical reduction of diazonium salts, including ionic liquids (Scheme 2). Such a disordered structure of PP layers has been already observed on many occasions. For instance, on a Fe surface a thick layer of PP is obtained by reduction of BD in ACN [12]. The reduction of p-butylbenzenediazonium bis(trifluoromethanesulfonyl)imide has been performed on carbon [50]; the surface presents a band at $824 \mathrm{~cm}^{-1}$ in the out of plane region, but other bands in the same region are not observed due to the low intensity of the spectrum on carbon. In the 
other studies concerning the reduction of diazonium salts in ionic liquid, the IR spectra in the out-of plane region are not reported [51-53].This is clearly the result of the uncontrolled growth of the layers due to highly reactive radicals.

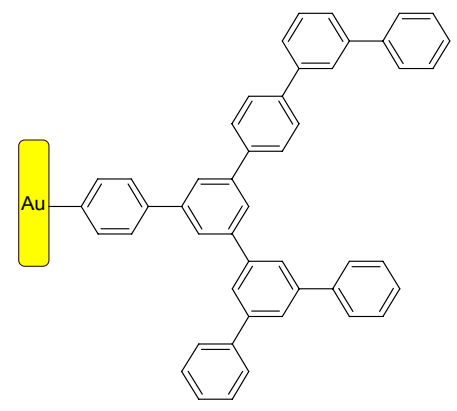

Scheme 2. Schematic representation of the assumed structure of a polyphenylene film obtained from the direct electrografting of $\mathrm{BD}$ in $\mathrm{ACN}$ or $[\mathrm{BMIm}]\left[\mathrm{PF}_{6}\right]$.

3.3. Preparation of films onto gold substrates by combining the electrochemical reduction of benzenediazonium salts and anodic electropolymerisation of biphenyl.

In a first series of experiments, the reduction of the diazonium salt and the oxidation of biphenyl were performed in the same $[\mathrm{BMIm}]\left[\mathrm{PF}_{6}\right]$ medium at a gold substrate: $5 \mathrm{mM} \mathrm{BD}$ and $0.2 \mathrm{M}$ biphenyl were dissolved in $[\mathrm{BMIm}]\left[\mathrm{PF}_{6}\right]$, and then 2 reduction cycles (between 0.2 and $-1.3 \mathrm{~V} v s \mathrm{Pt}, \mathrm{v}=0.1 \mathrm{~V} / \mathrm{s}$ ) followed by 3 oxidation cycles (between 0.1 and $2.5 \mathrm{~V} v s \mathrm{Pt}$, $\mathrm{v}=0.1 \mathrm{~V} / \mathrm{s}$ ). After extensive rinsing under ultrasonication, the thickness of the resulting film was measured by ellipsometry and a value equal to $31.0 \pm 4.0 \mathrm{~nm}$ was found. This method will be denominated one-pot method in the following.

The PPP film could also be obtained by grafting first a very thin layer by reduction of $\mathrm{BD}$ in aqueous acidic solution and then a layer of PPP is grown on top of the first one by oxidation of biphenyl. Figure 3 displays the cyclic voltammograms recorded during these two steps. A gold wafer was modified by electrochemical reduction of BD in situ generated from cold aqueous $10 \% \mathrm{HCl}$ containing $1 \mathrm{mM}$ of aniline and $1.1 \mathrm{mM}$ of sodium nitrite $(3$ scans 
between +0.4 and $-0.4 \mathrm{~V} v s(\mathrm{Ag} / \mathrm{AgCl})$ at $\mathrm{v}=50 \mathrm{mV} / \mathrm{s})($ Figure $3 \mathrm{~A})$. After a thorough rinsing (6 minutes in acetone under ultrasonication and then ultrapure water), the thickness of the obtained layer was measured as $1.9 \pm 0.6 \mathrm{~nm}$ by ellipsometry. The modified gold wafer was then used as an anode for the oxidation of $0.2 \mathrm{M}$ biphenyl in [BMIm] $\left[\mathrm{PF}_{6}\right]$ (3 scans at $\mathrm{v}=0.1$ $\mathrm{V} / \mathrm{s}$ between 0.1 and $2.5 \mathrm{~V}$ vs $\mathrm{Pt}$ ) (Figure 3B). Then the film was thoroughly rinsed as indicated above for the thin sublayer to remove any ungrafted matter on the surface. The thickness of the film increases to $15.6 \pm 3.0 \mathrm{~nm}$ after the electrochemical oxidation of biphenyl. This strategy that will be denominated as the two-pot experiment allows a fine control of the thickness of the primary layer. The first layer will be termed TL and the second one PPP.

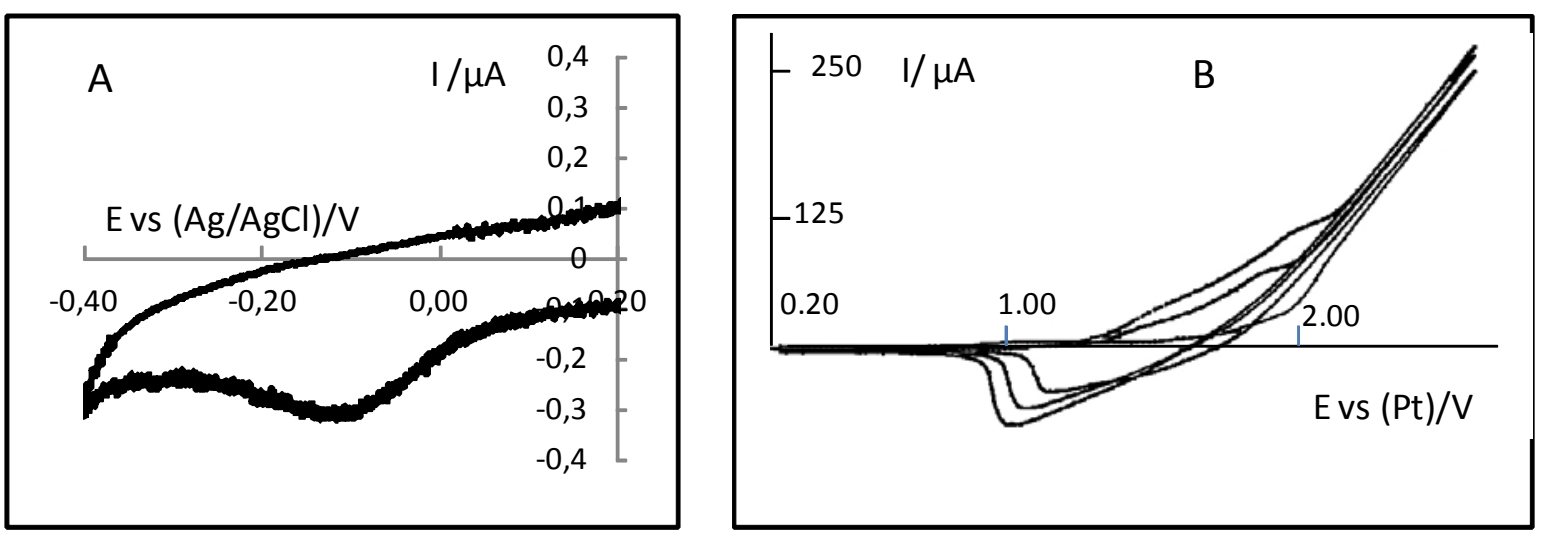

Figure. 3. A.Voltammogram of in situ generated $\mathrm{BD}$ at a gold electrode (aqueous $\mathrm{HCl}$ containing $1 \mathrm{mM}$ aniline and sodium nitrite), $\mathrm{v}=50 \mathrm{mV} / \mathrm{s}$, first scan. Reference: $\mathrm{Ag} / \mathrm{AgCl}$. B. Electropolymerization of $0.2 \mathrm{M}$ biphenyl in $[\mathrm{BMIm}]\left[\mathrm{PF}_{6}\right]$ at $\mathrm{v}=0.1 \mathrm{~V} / \mathrm{s}$, onto the modified gold electrode as described in A. Quasi-Reference Pt.

\subsection{Spectroscopic characterizations of the films obtained through the} elctropolymerization of biphenyl on the grafted surface. Evidencing the formation of regular PPP films.

The one-pot and two-pot films were first characterized using IR spectroscopy (Figure 4). For both of them, the bands of the IRRAS spectrum can be interpreted as characteristic of a 
poly(para-phenylene) film by reference to literature data [19]: 1482 and $1398 \mathrm{~cm}^{-1}$ can be assigned to the ring vibration; $1001 \mathrm{~cm}^{-1}$ to in-plane hydrogen bending vibration of disubstituted benzene ring; $812 \mathrm{~cm}^{-1}$ to out-of-plane hydrogen $\mathrm{C}-\mathrm{H}$ vibration of 1,4disubstituted benzene ring, $763 \mathrm{~cm}^{-1}$ to out-of-plane hydrogen $\mathrm{C}-\mathrm{H}$ vibration of monosubstituted benzene ring and $696 \mathrm{~cm}^{-1}$ ring distortion deformation of monosubtituted benzene ring. In the out-of-plane region, the two spectra of Figure 4 are very different from that of Figure 2. These results clearly demonstrate that the polymer deposited onto the metallic substrate shows para-disubstitution, indicating the formation of a highly regular PPP layer. It is worth outlining that such a PPP layer could not be obtained from the electrochemical reduction of BD alone as demonstrated in section 3.2

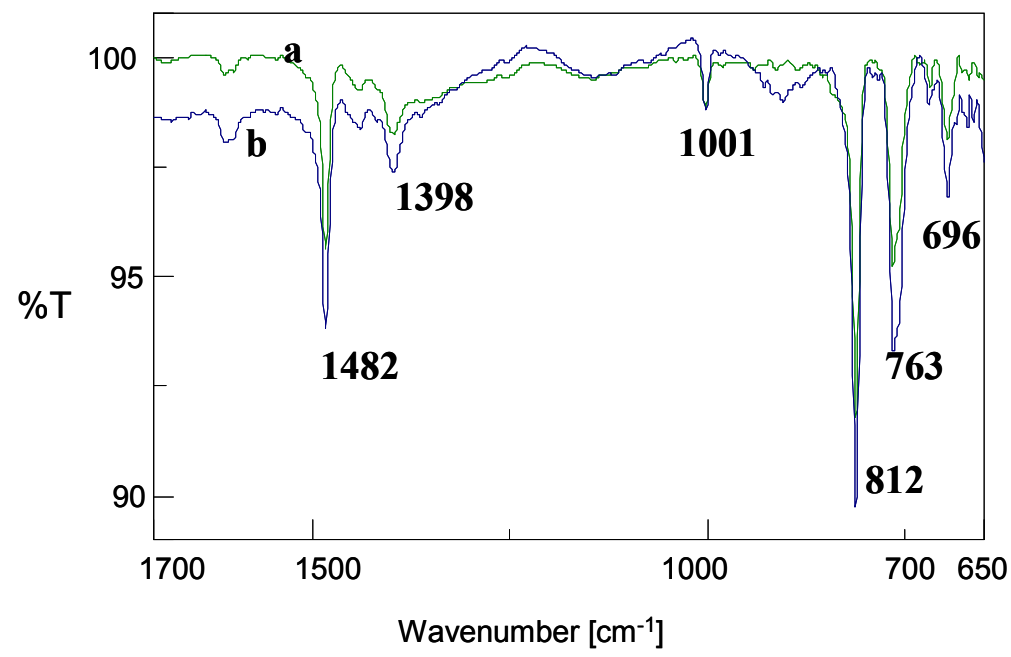

Figure 4. IRRAS spectrum of a gold plate a) modified by the two-pot method: reduction of BD generated in situ in aqueous acidic solution and then by oxidation of biphenyl in $[\mathrm{BMIm}]\left[\mathrm{PF}_{6}\right] \mathrm{b}$ ) modified by the one-pot method

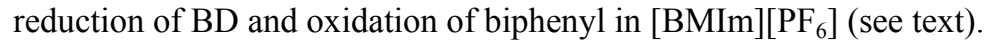

The presence of a PPP layer is further confirmed by Time-of-Flight Secondary ion mass spectrometry (ToF-SIMS) through the decreased height of the $\mathrm{Au}^{+}$peak (Figure 5). The polyphenylene structure is demonstrated by the presence of negative peaks at $\mathrm{m} / \mathrm{z}=73.01$ and 77.05, assigned to $\mathrm{C}_{6} \mathrm{H}^{-}$and $\mathrm{C}_{6} \mathrm{H}_{5}^{-}$, respectively (Figure 5). 

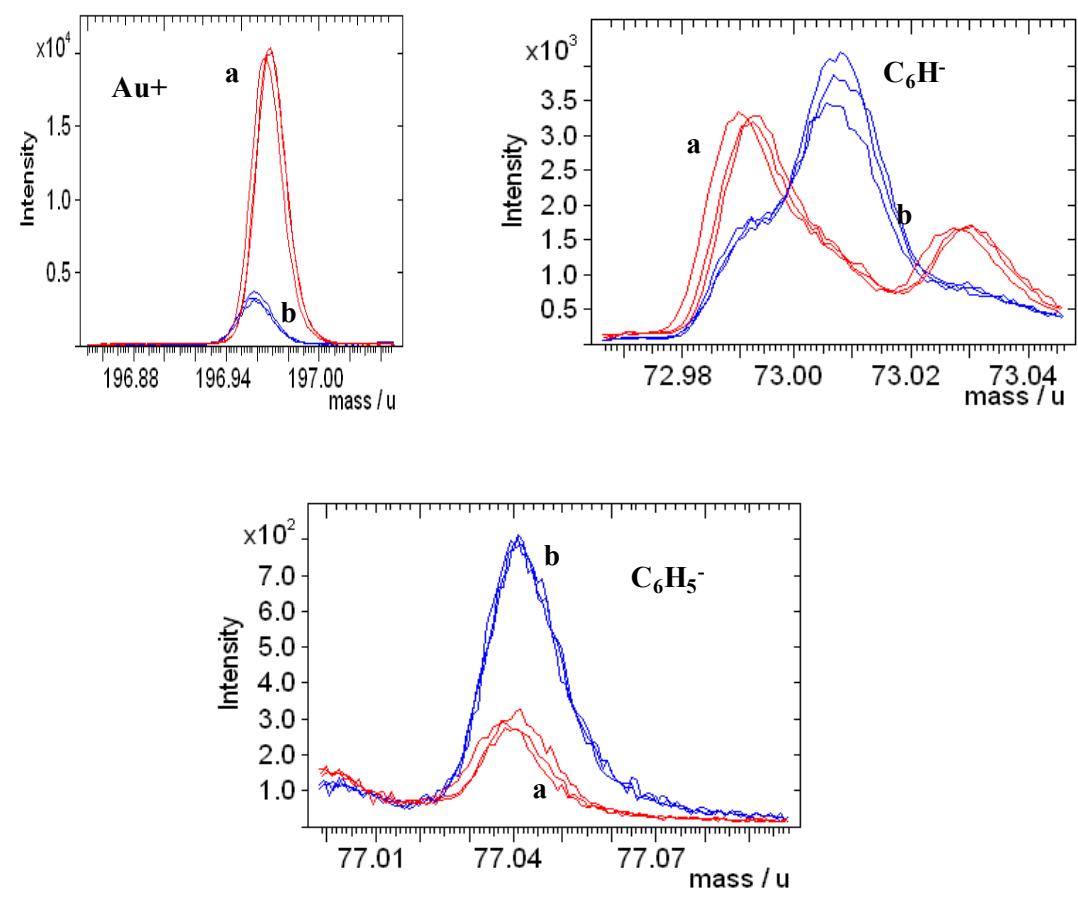

Figure 5. ToF-SIMS spectra of a) a bare Au surface, b) a PPP-grafted Au surface (from electrochemical reduction of in situ generated $\mathrm{BD}$ in an aqueous acidic medium followed by the electrochemical oxidation of 0.2 $\mathrm{M}$ biphenyl in $\left.[\mathrm{BMIm}]\left[\mathrm{PF}_{6}\right]\right)$. Multiple lines indicate that the spectrum has been recorded at different places on the substrate. These spectra were acquired on a two-pot sample.

The number of phenyl repeat units can be calculated from the thickness of the layer. Jiang et $a l$. have examined by DFT calculations the phenyl groups attached to gold surface through the reduction of diazonium salts [11]. They have shown that the phenyl groups are tilted by $38^{\circ}$ with respect to the surface normal and the length of a phenyl repeat unit is $\sim 0.54 \mathrm{~nm}$. Therefore, a film of linear PPP chains with a thickness of $15.6 \mathrm{~nm}$ (two-pot method) (including the thickness of the primer layer) is equivalent to approximately 36 phenyl groups. The same calculation applied to the $31.0 \mathrm{~nm}$ film would correspond to $\sim 72$ phenyl groups (one-pot method). On the whole, the values for the number of repeat units are consistent with those reported for electrochemically-grown PPP films [36,43].

Remarkably, the gold plates modified with the combined strategy, electrochemical reduction of benzenediazonium salts/oxidative polymerization of biphenyl in $[\mathrm{BMIm}]\left[\mathrm{PF}_{6}\right]$, also present a nice blue fluorescence as expected for poly(para-phenylene) ( $\lambda_{\max }=363 \mathrm{~nm}$ for 
a polyphenylene dendrimer [54]) (Figure 6). This analysis strengthens the idea that ordered PPP films are formed on the surface. While a detailed analysis of the luminescence properties of the resulting film is beyond the scope of this paper, this result deserves being mentioned since the blue light emission is a prerequisite for considering any potential applications in optoelectronics.

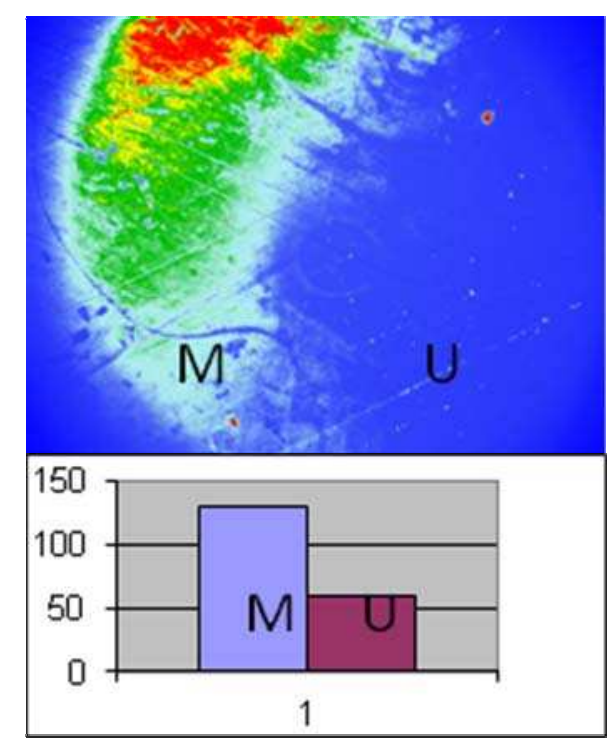

Figure 6. Fluorescence image (arbitrary colors) and relative fluorescence units of the limit between the modified layer (M) and the bare (unmodified) gold (U) surface.

3.5. Electropolymerization of biphenyl on the grafted surface in $[B M I m]\left[P F_{6}\right]$ ionic liquid to form regular PPP films. Importance of the nature of the ionic liquid

The different analyses made on the one-pot or two-pot procedure point to the formation of highly regular polyphenylene films mainly constituted of para-substitution. In the first step of the presented strategy, the BD leads through a one electron concerted reduction to a phenyl radical that binds to the substrate to form a very thin PP layer (equivalent to less than 4 phenyl repeat units) attached to the substrate[3,55]. It has been shown that such thin layers could remain conductive enough [6] to be further derivatized [5], allowing the electropolymerization to be achieved onto these modified surfaces. Since the structure of the 
polyphenylene film grown in conventional electrolytes $\left(\mathrm{ACN}+\mathrm{NBu}_{4} \mathrm{BF}_{4}\right.$ as supporting salt or even in $[\mathrm{BMIm}]\left[\mathrm{PF}_{6}\right]$ ) is, as shown at the beginning of this paper, highly disordered with several types of substitution and cross-linking, it is clear that the consecutive electropolymerization step is essential to build the regular PPP on the surface, previously modified with a TL layer as thin as possible. In the electrooxidative growth of the layer, the ionic liquid has a dramatic influence on the structure of the polyphenylene layers. Mechanistic studies of the electropolymerization process in ionic liquids showed that the critical steps of the process are identical to those observed in conventional media [56]: it is known that mainly radical cation-radical cation coupling takes place during the electrooxidative polymerization process to form longer oligomers [57]. Obviously, the large availability of the counter ion in the ionic liquid is a favorable parameter with respect to this synthetic route and this probably plays a role in stabilizing the produced radical cations intermediates. The ionic liquids are, in principle, media with low nucleophilicity and are free from molecular solvent. Thus one can prevent side reactions of a solvent molecule with the moderately stable radical cation generated during the electrochemical process; yielding better structured polymers. However, the nature of ionic liquid is of importance and a careful choice of the anion/cation combination has to be made.

Instead of using $[\mathrm{BMIm}]\left[\mathrm{PF}_{6}\right]$ for the electropolymerization step, we employed another, but still hydrophobic, ionic liquid: 1-butyl-3-methyl-imidazolium bis(trifluoromethanesulfonyl)imide $[\mathrm{BMIm}]\left[\mathrm{NTf}_{2}\right]$. The IR analyses demonstrated that the resulting layers were formed of highly disordered polyphenylene layers, exhibiting different types of substitution patterns. It is highly probable that the Lewis basicity of the ionic liquid plays a role in this process. The larger the basicity of the medium, the more easily the electrogenerated cation radical intermediates is attacked. Consequently, short chains polymers with defects would be obtained. The Lewis basicity of the ionic liquids was found to mainly 
depend on the ionic liquid anion and can be ordered according to rising Lewis basicity $\mathrm{PF}_{6}^{-}<$ $\mathrm{BF}_{4}{ }^{-}<\mathrm{NTf}_{2}^{-}$[58]. Accordingly, it can be noted that the tris(pentafluorethyl)trifluorophosphate anion that composed the ionic liquid used by Endres and co-workers to form regular PPP layers has also very low Lewis basicity $[42,43]$. The nucleophilic properties of $\mathrm{NTf}_{2}$ anion have negative effect on the polymerization process, being responsible, at least partially, for the formation of disordered polyphenylene layers. Another point that can be invoked to rationalize the beneficial effect of the ionic liquid in this process is the possible stabilization of the $\pi$-segments along the polymer chain due to some interactions with the imidazolium cations, thus improving the electronic properties and the stability of the polymer as suggested by Endres et al. in a recent work [59].

\subsection{Evidencing the binding of the PPP layer to the gold substrate.}

Having demonstrated the presence of regular PPP on the surface, the last point to be addressed is the binding of the PPP layer to gold. As a first qualitative indication, after the initial 6 min-rinsing under sonication, three further rinsing under the same conditions do not show any modification of the IRRAS spectrum, namely no decrease in the absorption band intensities, suggesting that the layer is strongly bound to the metal surface. After this ultrasonic rinsing in acetone, the gold plate is extracted for 3 hours in boiling toluene. Despite this harsh treatment, the IRRAS spectrum is moderately affected. For instance, the characteristic and more intense $812 \mathrm{~cm}^{-1}$ band shows a decrease in intensity by less than $25 \%$ (Figure 7). 

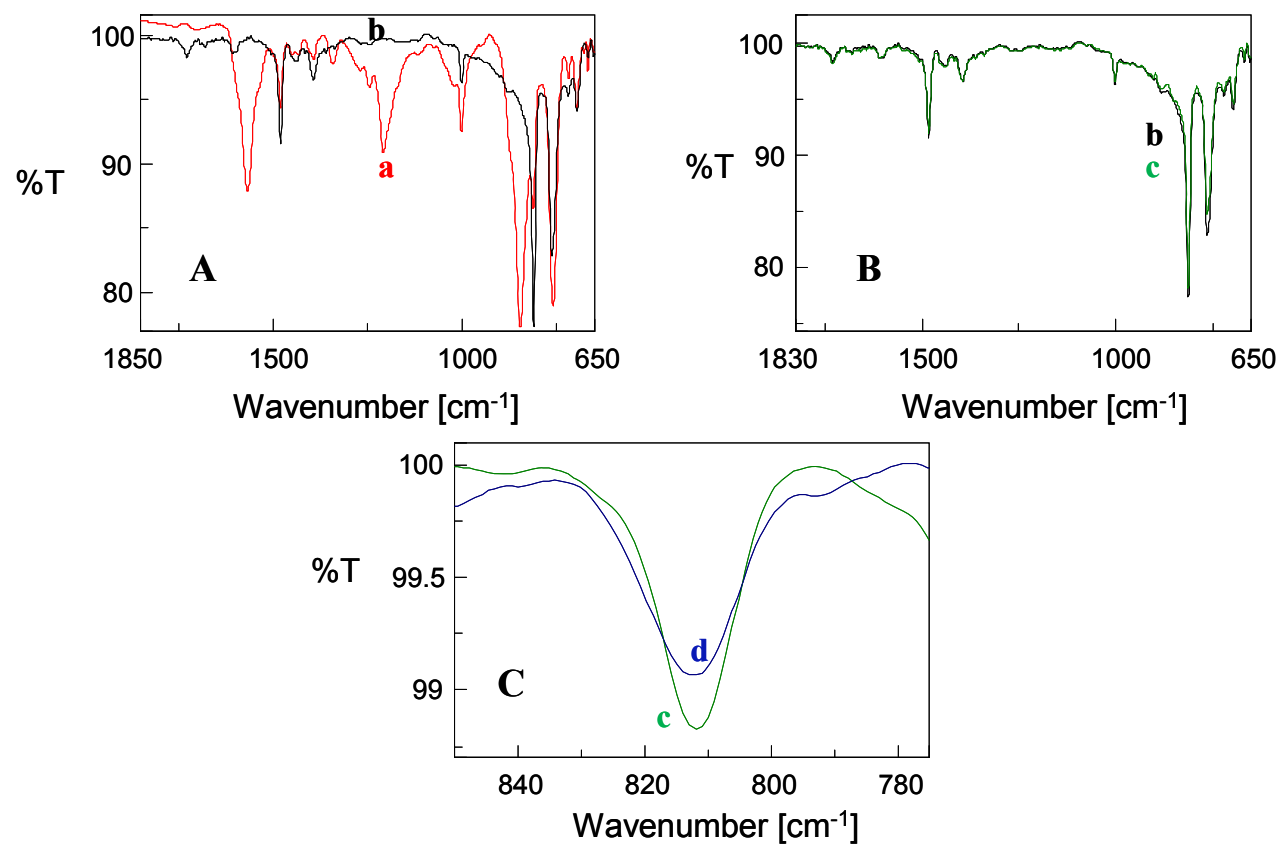

Figure. 7. IRRAS spectra of Aa) a gold plate after the electrografting of PPP according to the two-pot procedure. $\mathrm{Ab}, \mathrm{Bb})$ After ultrasonication in acetone (6 minutes). Bc, Cc) After a further (18 min) rinsing under the same conditions. Cd) After further extraction with boiling toluene for 3 hours.

This strongly suggests that the PPP layer is not simply $\pi$-stacked in the thin PP layer obtained by reduction of the diazonium salt. Interestingly, a magnification of the first scan in cyclic voltammogramms recorded for the oxidation of biphenyl in the ionic liquid for a bare gold electrode and for a grafted surface shows a sharp difference in the current height before the oxidation peak of biphenyl (figure 8). It can be observed a significant current intensity on the grafted surface while on the bare surface, it is close to zero, suggesting that the TL film undergoes an oxidation process before biphenyl starts being oxidized. Then a biphenyl monomer in solution may have a chance to react with a surface cation radical formed upon oxidation of the TL layer and to form a polymer chain. 


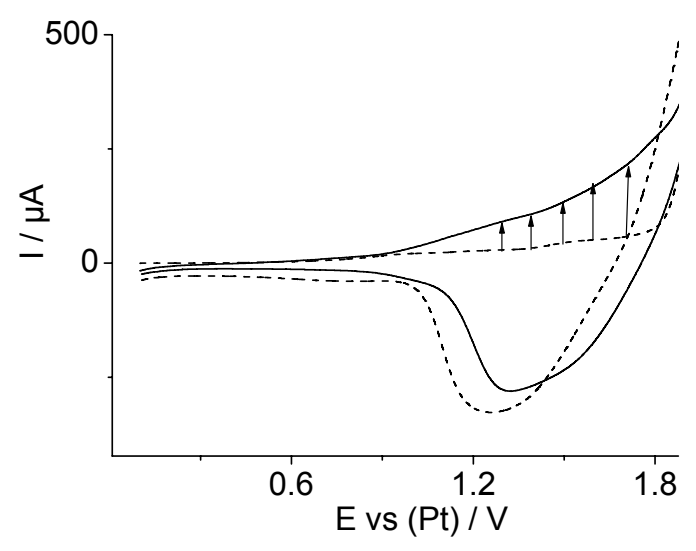

Figure 8. Comparison of the first scan monitored in cyclic voltamogramms (magnification in the $0.1-1.8 \mathrm{~V}$ potential range) for oxidation of biphenyl $(0.2 \mathrm{M})$ in $[\mathrm{BMIm}]\left[\mathrm{PF}_{6}\right]$ on a bare gold electrode (dashed line) and on a grafted surface (solid line). Arrows show the increase of current intensity

Analyses by ToF-SIMS were conducted to further evidence the binding of PPP layers to the metallic surface. ToF-SIMS spectra show the presence of positive fragments at $\mathrm{m} / \mathrm{z}=$ $350.06\left(\mathrm{AuC}_{12} \mathrm{H}_{9}{ }^{+}\right), 455.12\left(\mathrm{AuC}_{20} \mathrm{H}_{18}{ }^{+}\right), 603.17\left(\mathrm{AuC}_{32} \mathrm{H}_{22}{ }^{+}\right) ; 753.25\left(\mathrm{AuC}_{44} \mathrm{H}_{28}{ }^{+}\right)$and of negative fragments at $\mathrm{m} / \mathrm{z}=257.95\left(\mathrm{AuC}_{5} \mathrm{H}^{-}\right), 270.87\left(\mathrm{AuC}_{6} \mathrm{H}^{-}\right), 271.97\left(\mathrm{AuC}_{6} \mathrm{H}_{3}{ }^{-}\right), 466.94$ $\left(\mathrm{Au}_{2} \mathrm{C}_{6} \mathrm{H}^{-}\right)$(Figure 8). 

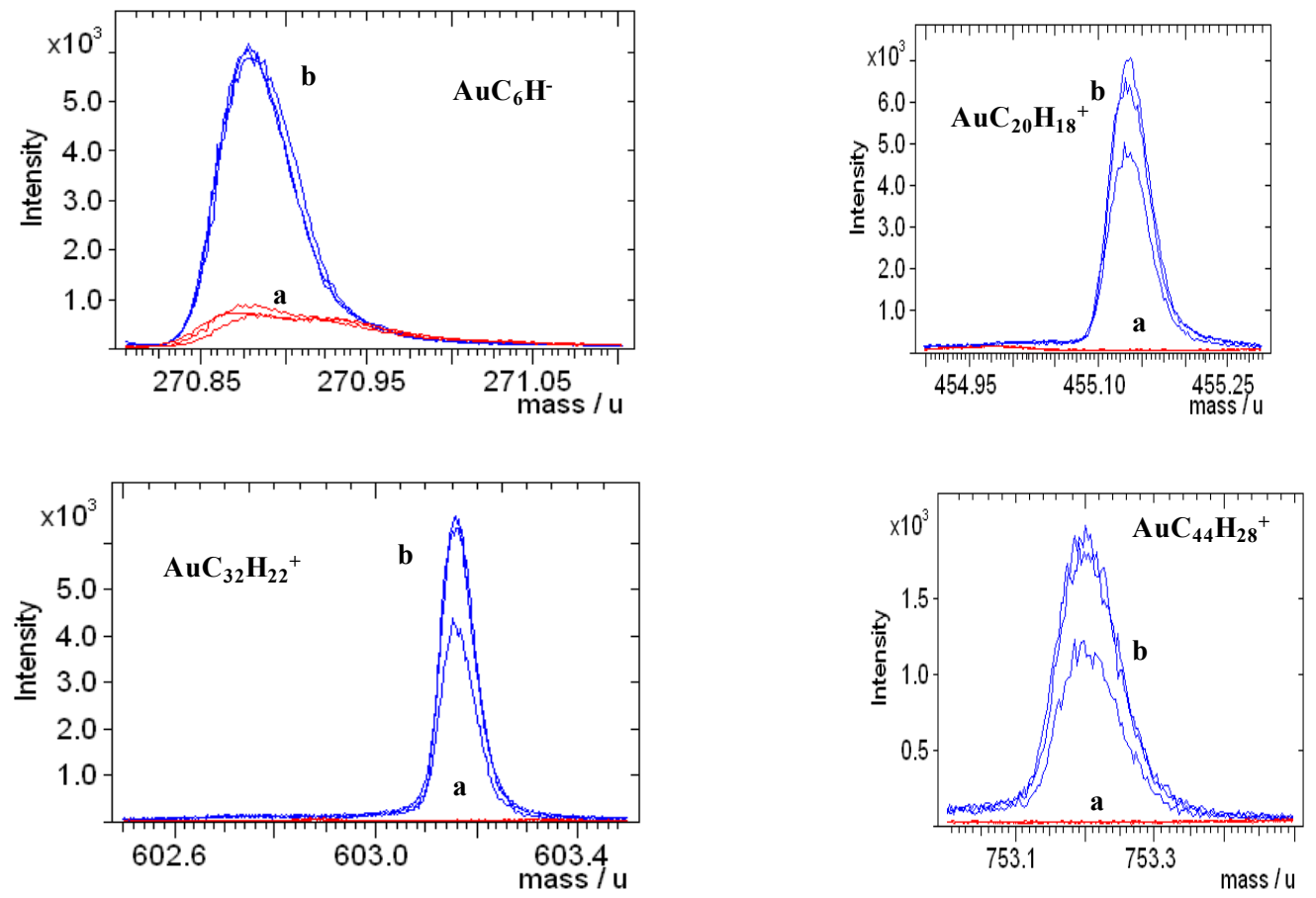

Figure 9. Tof-Sims spectra of a) a bare Au substrate, b) fragments containing both a gold atom and a carbon fragment after the grafting of a PPP layer by the two-pot procedure. Multiple lines indicate that the spectrum has been recorded at different places on the substrate

These fragments can be attributed to parts of the PPP layer grafted either to one or two gold atoms. The presence of $\mathrm{AuC}_{32} \mathrm{H}_{22}{ }^{+}$and $\mathrm{AuC}_{44} \mathrm{H}_{28}{ }^{+}$indicates that fragments containing 32 and 44 carbon atoms are attached to the gold substrate, which obviously exceeds the expected fragments for the primary layer alone and then corresponds to part of the structure $A u$-PPP

The ToF-SIMS technique also provides mass spectral image of a surface sample, allowing the mapping of surface constituents with a high spatial resolution. Prior to the imaging experiments, the PPP layer was deliberately scratched. Imaging of the scratch and its vicinity was performed to evidence difference in the distribution of surface constituents inside and outside the scratch (Figure 9). Interestingly, signals corresponding to $\mathrm{Au}^{+}$ions (Figure 9a) mostly appear inside the scratch whereas signals related to the sum of the ions $\left[\mathrm{AuC}_{20} \mathrm{H}_{18}{ }^{+}+\right.$ $\mathrm{AuC}_{32} \mathrm{H}_{22}{ }^{+}+\mathrm{AuC}_{44} \mathrm{H}_{28}{ }^{+}$] are mainly present outside the scratch (Figure 9b). Figure 9c displays the imaging of the layer with the signals for the sum $\left[\mathrm{Au}^{+}+\mathrm{AuC}_{20} \mathrm{H}_{18}{ }^{+}+\mathrm{AuC}_{32} \mathrm{H}_{22}{ }^{+}\right.$ 
$\left.+\mathrm{AuC}_{44} \mathrm{H}_{28}{ }^{+}\right]$(blue contrast). Obviously, the ions containing both $\mathrm{Au}$ and part of the organic layer are mainly located outside the scratch, thus confirming the presence of a polyphenylene layer onto the gold substrate. Inspection of the images unambiguously evidences that the Au$\mathrm{C}$ (layer) bond is present everywhere onto the surface sample except inside the scratch. From these observation and the mass spectrum analyses, it can be concluded that the PPP layer is covalently attached to the gold surface
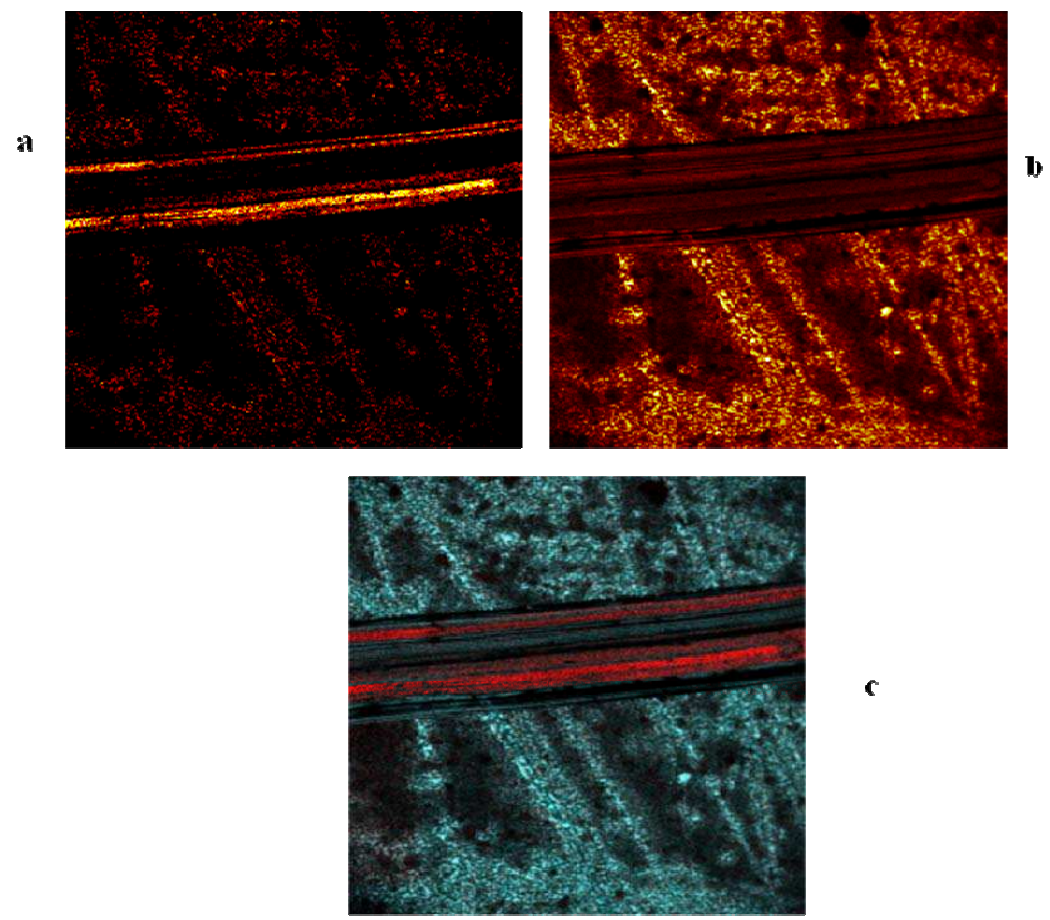

Figure 10. Tof-Sims image of a scratch in the layer with a) $\mathrm{Au}^{+}$ions (yellow contrast), b) $\mathrm{AuC}_{20} \mathrm{H}_{18}{ }^{+}+$ $\mathrm{AuC}_{32} \mathrm{H}_{22}{ }^{+}+\mathrm{AuC}_{44} \mathrm{H}_{28}{ }^{+}$ions (yellow contrast) and c) the sum $\mathrm{Au}^{+}+\mathrm{AuC}_{20} \mathrm{H}_{18}{ }^{+}+\mathrm{AuC}_{32} \mathrm{H}_{22}{ }^{+}+\mathrm{AuC}_{44} \mathrm{H}_{28}{ }^{+}$(blue contrast).

\section{Conclusions}

As a conclusion, this paper describes the preparation of highly regular poly(para-phenylene) covalently bonded to gold layers with thicknesses in the $10-100 \mathrm{~nm}$ range. The resulting material shows higher resistance toward aggressive treatments (extensive ultrasonic rinsing, soxhlet extraction in boiling toluene) than the PPP films simply deposited onto surface by electropolymerization technique (that delaminate upon rinsing with acetone). Moreover, it is 
worth outlining that the approach described here is easy to operate since it does not require performing the electrochemical polymerization in a glove box and since $[\mathrm{BMIm}]\left[\mathrm{PF}_{6}\right]$ is a commonly-used ionic liquid. This strategy may be advantageous for manufacturing devices using PPP, requiring the wiring of the layers to the substrate. This method could be applied to different substrates including carbon, platinum, ITO... As it involves an oxidation, the substrate must resist at quite positive potentials. It would be interesting to carry out the strategy on more common and cheaper substrates; experiments are under course to test the approach on substrates such as stainless steel and silicon under ultra dry conditions [60].

\section{References}

[1] M. M. Chehimi, Aryl Diazonium Salts. New Coupling Agents in Polymer and Surface Science, Wiley-VCH:Weinheim, 2012.

[2] J. Pinson, F. Podvorica, Attachment of organic layers to conductive or semiconductive surfaces by reduction of diazonium salts, Chem. Soc. Rev. 34 (2005) 429.

[3] D. Bélanger, J. Pinson, Electrografting: a powerful method for surface modification, Chem. Soc. Rev. 40 (2011) 3995.

[4] J. J. Gooding, Ciampi, S. The molecular level modification of surfaces: from selfassembled monolayers to complex molecular assemblies, Chem. Soc. Rev. 40 (2011) 2704.

[5] S. Mahouche-Chergui, S. Gam-Derouich, C. Mangeney, M. M. Chehimi, Aryl diazonium salts: a new class of coupling agents for bonding polymers, biomacromolecules and nanoparticles to surfaces, Chem. Soc. Rev. 40 (2011) 4143.

[6] R. L. McCreery, Advanced Carbon Electrode Materials for Molecular Electrochemistry, Chem. Rev. 108 (2008) 2646.

[7] D. K. Aswal, S. P. Koiry, B. Jousselme, S. K. Gupta, S. Palacin, J. Yakhmi, Hybrid molecule-on-silicon nanoelectronics: Electrochemical processes for grafting and printing of monolayers, Physica E 41 (2009) 325.

[8] K. Boukerma, M. M. Chehimi, J. Pinson, C. Blomfield, X-ray Photoelectron Spectroscopy Evidence for the Covalent Bond between an Iron Surface and Aryl Groups Attached by the Electrochemical Reduction of Diazonium Salts, Langmuir 19 (2003) 6333.

[9] C. Combellas, F. Kanoufi, J. Pinson, F. I. Podvorica, Time-of-Flight Secondary Ion Mass Spectroscopy Characterization of the Covalent Bonding between a Carbon Surface and Aryl Groups, Langmuir 21 (2005) 280. 
[10] L. S. Laurentius, R. Stoyanov, S. Gusarov, A. Kovalenko, R. B. Du, G. P. Lopinski, M. T. McDermott, Diazonium-Derived Aryl Films on Gold Nanoparticles: Evidence for a Carbon-Gold Covalent Bond, ACS Nano 5 (2011) 4219.

[11] D.-E. Jiang, B. G. Sumpter, S. Dai, Structure and Bonding between an Aryl Group and Metal Surfaces, J. Am. Chem. Soc. 128 (2006) 6030.

[12] A. Adenier, C. Combellas, F. Kanoufi, J. Pinson, F. I. Podvorica, Formation of Polyphenylene Films on Metal Electrodes by Electrochemical Reduction of Benzenediazonium Salts, Chem.Mater. 18 (2006), 2021.

[13] J. C. Love, L. A. Estroff, R. Kriebel, G. Nuzzo, G. M. Whitesides, Self-Assembled Monolayers of Thiolates on Metals as a Form of Nanotechnology, Chem. Rev. 105 (2005) 1103.

[14] Z. Bao, Organic materials for thin film transistors, Material Matters 3 (2007) 4.

[15] S. Luebben, S. Sapp, New conducting and semiconducting polymers for plastic electronics, Material Matters 3 (2007) 11.

[16] E. Polikarpov, M. E. Thompson, Achieving high efficiency in organic light-emitting devices, Material Matters 3 (2007) 21.

[17] Q. Pei, Light emitting polymers, Material Matters 3 (2007) 26.

[18] J.-L. Bredas, D. Beljonne, V. Coropceanu, J. Cornil, Charge-Transfer and EnergyTransfer Processes in $\pi$-Conjugated Oligomers and Polymers: A Molecular Picture, Chem. Rev. 104 (2004) 4971.

[19] P.-C. Lacaze, S. Aeiyach, J.-C. Lacroix, , Poly(p-phenylenes):Preparation Techniques and Properties, in: Nalwa, H. S. (Ed.) Handboook of Organic Conductive Molecules and Polymers, Vol.2, Ch. 6, John Wiley, New York,1997, p. 205

[20] M. Banerjee, R. Shukla, R. Rathore, Synthesis, Optical, and Electronic Properties of Soluble Poly-p-phenylene Oligomers as Models for Molecular Wires, J. Am. Chem. Soc. 131 (2009) 1780.

[21] L. W. Shacklette, H. Eckhardt, R. R. Chance, G. G. Miller, D. M. Ivory, R. H. Baughman, Solid-state synthesis of highly conducting polyphenylene from crystalline oligomers, J. Chem. Phys. 73 (1980) 4098.

[22] J. H. Burroughes, D. D. C. Bradley, A. R. Brown, R. N. Marks, R. H. Friend, P. L. Burn, A. B. Holmes, Light-emitting diodes based on conjugated polymers, Nature (1990) 347.

[23] G. Grem, G. Leising, Electroluminescence of "wide-bandgap" chemically tunable cyclic conjugated polymers, Synth. Met. 57 (1993) 4105.

[24] F. Meghdadi, S. Tasch, B. Winkler, W. Fischer, F. Stelzer, G. Leising, Blue electroluminescence devices based on parahexaphenyl, Synth. Met. 85 (1997) 1441.

[25] J. W. Baur, S. Kim, P. B. Balanda, J. R. Reynolds, M. F. Rubner, Thin-Film LightEmitting Devices Based on Sequentially Adsorbed Multilayers of Water-Soluble Poly(pphenylene)s, Adv. Mater. 10 (1998) 1452. 
[26] A. Kraft, A. C. Grimsdale, A. B. Holmes, Electroluminescent Conjugated PolymersSeeing Polymers in a New Light, Angew. Chem. Int. Ed. 37 (1998) 402.

[27] K. N. Baker, A. V. Fratini, T. Resch, H. C. Knachel, W. W. Adams, E. P. Socci , B. L. Farmer, Crystal structures, phase transitions and energy calculations of poly(p-phenylene) oligomers, Polymer 34 (1993) 1571.

[28] D. M. Gale, Properties of fabricated poly-p-phenylene, J. Appl. Polym. Sci. 22 (1978) 1971.

[29] I. Osaka, G. Sauvé, R. Zhang, T. Kowalewski, R. D. McCullough, Novel ThiopheneThiazolothiazole Copolymers for Organic Field-Effect Transistors, Adv. Mater. 19 (2007) 4160 .

[30] M. Koppe, M. Scharber, C. Brabec, W. Duffy, M. Heeney, I. McCulloch, Polyterthiophenes as Donors for Polymer Solar Cells, Adv. Funct. Mater. 17 (2007) 1371.

[31] Y. Wu, X. Hao, J. Wu, J. Jina, X. Ba, Pure Blue-Light-Emitting Materials: Hyperbranched Ladder-Type Poly(p-phenylene)s Containing Truxene Units, Macromol. 43 (2010) 731.

[32] J. A. Lipton-Duffin, O. Ivasenko, D. F. Perepichka, F. Rosei, Synthesis of Polyphenylene Molecular Wires by Surface-Confined Polymerization, Small 5 (2009) 592.

[33]J. Heinze, B. A. Frontana-Uribe, S. Ludwigs, Electrochemistry of Conducting Polymers-Persistent Models and New Concepts, Chem. Rev. 110 (2010) 4724

[34] A. F. Shepard, B. F. Dannels, Interfacial anodic polymers from benzene in hydrogen fluoride, J. Polym. Sci Polym Chem. 4 (1966) 511.

[35] R. M. Q. Mello, J. P. M. Serbena, A. R. V. Benvenho, I. A. Hummelgen, Electrochemical preparation of poly(p-phenylene) thin films, Solid State Electrochem. 7 (2003) 463.

[36] S. Aieyach, P. Soubiran, P.-C. Lacaze, G. Froyer, Y. Pelous, A study of the structure and morphology of poly(p-phenylene) films electrosynthesized in liquid $\mathrm{SO}_{2}$ with different salts at low temperatures, Synth. Met. 68 (1995) 213.

[37] S. Aeiyach, P.-C. Lacaze, Electropolymerization of benzene and biphenyl in organic media: Influence of different parameters (solvent, water, acidity, salt) on the formation of polyparaphenylene films (PPP), J. Polym. Sci., Polym Chem. 27 (1989) 515.

[38] J. Rault-Berthelot, J. Tahri-Hassani, Anodic oxidation of biphenyl and p-terphenyl in dry $\mathrm{CH}_{2} \mathrm{Cl}_{2}+0.2 \mathrm{M} \mathrm{Bu}_{4} \mathrm{NBF}_{4}$. Towards poly(p-phenylene) possessing stable and reversible $\mathrm{p}-$ and n-doping processes, J. Electroanal. Chem. 408 (1996) 247.

[39] J. M. Pringle, M. Forsyth, and D. R. Macfarlane, Conducting Polymers in: Endres, F., A. P. Abbott, D. R. MacFarlane (Eds), Electrodeposition from ionic liquids, Chapter 9, eds, Wiley-VCH, Weinheim, 2008, p.167 and reference therein.

[40] T. Welton, Room-Temperature Ionic Liquids. Solvents for Synthesis and Catalysis, Chem. Rev. 99 (1999) 2071. 
[41] M. Armand, F. Endres, D. MacFarlane, H. Ohno, B. Scrosati, Ionic-liquid materials for the electrochemical challenges of the future, Nature Mater. 8 (2009) 621.

[42] S. Z. El Abedin, N. Borissenko, F. Endres, Electropolymerization of benzene in a room temperature ionic liquid, Electrochem. Commun. 6 (2004) 422.

[43] T. Carstens, S. Z. El Abedin, F. Endres, Electrosynthesis of Poly(para)phenylene in an Ionic Liquid: Cyclic Voltammetry and in Situ STM/Tunnelling Spectroscopy Studies, ChemPhysChem 9 (2008) 439.

[44 M. Wagner, C. Kvarnström, A. Ivaska, Room temperature ionic liquids in electrosynthesis and spectroelectrochemical characterization of poly(para-phenylene),_Electrochimica Acta. 55 (2010) 2527.

[45] L. M. Santos, J. Ghilane, C. Fave, P.-C. Lacaze, H. Randriamahazaka, L. M. Abrantes, J.-C. Lacroix, Electrografting Polyaniline on Carbon through the Electroreduction of Diazonium Salts and the Electrochemical Polymerization of Aniline, J. Phys. Chem. C 112 (2008) 16103.

[46] J. Lyskawa, D. Bélanger, Direct Modification of a Gold Electrode with Aminophenyl Groups by Electrochemical Reduction of in Situ Generated Aminophenyl Monodiazonium Cations, Chem. Mater. 18 (2006) 4755.

[47] J. Dupont, C. S. Consorti, P. A. Z. Suarez, R. F. de Souza, Preparation of 1-Butyl-3methylimidazolium-based room temperature ionic liquid, Org. Synth. 79 (2002) 236.

[48] G. Socrates, Infrared and Raman Characteristic group Frequencies, Wiley, Weinheim, $3^{\circ}$ edition, 2000.

[49] M.-C. Pham, S. Aeiyach, J. Moslih, P. Soubiran, P.-C. Lacaze, An in-situ multiple internal reflection Fourier transform infrared spectroscopic (MIRFTIRS) investigation of the growth mechanism of polyphenylene during electrooxidation of biphenyl in methylene dichloride, J. Electroanal. Chem. 277 (1990) 327.

[50] C. Liang, J.-F. Huang, Z. Li, H. Luo, S. Dai, A Diazonium Salt-Based Ionic Liquid for Solvent-Free Modification of Carbon, Eur. J. Org. Chem. (2006) 586.

[51] J. Ghilane, P. Martin, O. Fontaine, J.-C. Lacroix, H. Randriamahazaka, Modification of carbon electrode in ionic liquid through the reduction of phenyl diazonium salt. Electrochemical evidence in ionic liquid, Electrochem. Comm. 10 (2008) 1060.

[52] P. Actis, G. Caulliez, G. Shul, M. Opallo, M. Mermoux, B. Marcus, R. Boukherroub, S. Szunerits, Functionalization of Glassy Carbon with Diazonium Salts in Ionic Liquids, Langmuir 24 (2008) 6327

[53] Z. Jin, J. R. Lomeda, B. K. Price, W. Lu, Y. Zhu, J. M. Tour, Mechanically Assisted Exfoliation and Functionalization of Thermally Converted Graphene Sheets, Chem. Mater. 21 (2009) 3045.

[54] D. Liu, S. De Feyter, M. Cotlet, Alina Stefan, U.-M. Wiesler, A. Herrmann, D. GrebelKoehler, J. Qu, K. Müllen, F. C. De Schryver, Fluorescent Self-Assembled Polyphenylene Dendrimer Nanofibers, Macromol. 36 (2003) 5918. 
[55] P. Doppelt, G. Hallais, J. Pinson, F. Podvorica, S. Verneyre, Surface Modification of Conducting Substrates. Existence of Azo Bonds in the Structure of Organic Layers Obtained from Diazonium Salts, Chem.Mater. 19, (2007) 4570.

[56] J. Heinze, A. Rasche, M. Pagels, B. Geschke, On the Origin of the So-Called Nucleation Loop during Electropolymerization of Conducting Polymers, J. Phys. Chem. B 111 (2007) 989.

[57] P. Hapiot, P. Audebert, Fast electrochemical studies of the polymerization mechanisms of pyrroles and thiophenes. Identification of the first steps. Existence of $\pi$-dimers in solution, Synth. Met. 75 (1995) 95.

[58] J. Bartosik, A.-V. Mudring, $[\mathrm{Ni}(\operatorname{tmen})(\mathrm{acac})]\left[\mathrm{B}(\mathrm{Ph})_{4}\right]$ a probe for the anion basicity of ionic liquids, Phys.Chem. Chem. Phys. 12 (2010) 4005.

[59] S. Ahmad, T. Carstens, R. Berger, H.-J. Butt, F. Endres, Surface polymerization of (3,4ethylenedioxythiophene) probed by in situ scanning tunneling microscopy on $\mathrm{Au}(111)$ in ionic liquids, Nanoscale 3 (2011) 251.

[60] S. Fellah, F. Ozanam, J.-N. Chazalviel, J. Vigneron, A. Etcheberry, M. J. Stchakovsky, Grafting and Polymer Formation on Silicon from Unsaturated Grignards: I- Aromatic Precursors, J. Phys. Chem. B 110 (2006) 1665. 